in such a small amount of time. Without even treating this individual, we may have changed not only their dental health for life, but also their child's dental health.

This experience led me to understand the true worth of every minute of every dental appointment. Whilst it may be something we do day in day out, to others it is a strange and memorable event and so everything we say or do will possibly have a long lasting effect on a patient. Some of us may think that a full set of new anterior crowns or braces can change a person's life but based on this experience, I feel that even a single check-up can change a person's life and/or dental health for life. A new patient who comes into your clinic tomorrow may become a lifelong patient of your practice based off that single 15 minute appointment. I'm sure we all understand the positive benefits of this to the patient's lifelong dental health and possibly even their friends or family.

I think that if we all carry this thought throughout our dental careers it will not only be beneficial to our morale and motivation, but also to patients and the general perception of dentistry.

A. Jafarian, by email DOI: $10.1038 /$ sj.bdj.2016.799

\section{Antimicrobial resistance}

\section{The Glasgow OMF model}

Sir, in response to the letter by Singh ${ }^{1}$ highlighting the challenges of the infection workload in oralmaxillofacial (OMF) surgery and access to microbiology advice from clinical oral microbiologists (COMs) we outline how the service is utilised in Glasgow. In NHS Glasgow and Clyde Region there is one clinically active oral microbiologist who works with the maxillofacial services at the Queen Elizabeth University Hospital (QEUH) and Glasgow Dental Hospital. The regional OMF unit runs a trauma and surgical oncology service that includes management of severe odontogenic infections. There is a weekly ward round (Tuesdays 08:00) with the OMF team where cases, microbiology specimens, results and antimicrobial treatment plans are discussed and reviewed. Microbiology reports being reviewed the previous day from the laboratory e-reporting system by the COM. This process provides a vital antimicrobial stewardship link with improvements in clinical outcomes. An example of this is the move towards more prolonged antimicrobial treatment of complex ORN/MRONJ cases in collaboration between OMF with the outpatient antimicrobial treatment (OPAT) unit. The key to success of these interactions is teamwork as the COM is embedded in the medical microbiology services who combine to support a 24-hour and 365-days-a-year service to OMF. Howerver, this system does have its challenges as the COM is a clinical academic under the usual pressures for publications and grant funding. Furthermore, the diagnostic facilities are no longer located in the dental hospital which entails travelling to different sites.

In terms of undergraduate awareness of COM clinical training and scope of practice, ACOM and others have been lobbying for an increase in training numbers to the $\mathrm{COM}$ specialty for a number of years and have recommended to the Council of Dental School Deans that every school must have access to this level of academic and clinical support. In response to the scenario described in the letter the answer is the one that provides the best clinical outcome for the patient, ie multidisciplinary teamwork that includes access to a COM is the way forward. Perhaps pressure from the commissioning guide for dental specialties ${ }^{2}$ and activity by the postgraduate deaneries to create COM training posts will help improve patient outcomes from infection by improving access to expert advice?

A. Smith, C. Maclver, J. McMahon, C. Wales, I. Holland, by email

1. Singh N. Antimicrobial resistance: COMs and OMFSs. $\mathrm{Br}$ Dent J 2016; 221: 101.

2. NHS England. Commissioning Dental Specialties - Supporting Specialties. (In press.)

DOI: $10.1038 /$ sj.bdj.2016.800

\section{OMFS}

\section{Do your research}

Sir, in response to Ms Ahmed's letter, ${ }^{1}$ we support and add to Jennifer Graystone's online comments. We were the first dually qualified, surgically trained, FRCS positive, oral and maxillofacial surgery (OMFS) consultant couple in the UK, possibly in the world. We know, first hand, that careers in OMFS are compatible with family life (although our offspring Tom and Catherine might hold contrasting views).

We kindly suggest to Ms Ahmed that, before going to print, it is always beneficial to undertake a search of the literature, or at least Google. Surgeons must resist the temptation to extrapolate from the specific to the general without reviewing current evidence. At the British Association of Oral and Maxillofacial Surgeons Annual Scientific Meeting in
Brighton this summer, we presented a poster on Gender in Oral \& Maxillofacial Surgery (OMFS) which is available to view on ResearchGate. $^{2}$

Had Ms Ahmed found this poster, she would know that the first female OMFS consultant was appointed in 1967. In 2016, of 561 specialists and trainees identified in our study, $61(11 \%)$ are female making up $8 \%$ of consultants and specialists $(n=31)$ and $20 \%$ of trainees $(n=30)$. This compares favourably with other surgical specialties but there is clearly more progress to be made.

Finally, she might also have found two papers published online in the British Journal of Oral and Maxillofacial Surgery on 'Push' and 'Pull' Factors in OMFS which discuss the factors which draw and repel both genders to our specialty. ${ }^{3,4}$

\section{A. Begley, P. Magennis, by email}

1. Ahmed A. OMFS: Gender imbalance? Br Dent J 2016; 221: 372 .

2. Magennis $P$, Begley A. Gender of OMFS trainees and consultants change with time, first degree and risk of training failure. June 2016. Available at: https://www. researchgate.net/publication/308948818 (accessed October 2016).

3. Kent $\mathrm{S}$, Herbert $\mathrm{C}$, Magennis $\mathrm{P}$, Cleland J. What attracts people to a career in oral and maxillofacial surgery? A questionnaire survey. Br J Oral Maxillofac Surg 2016; doi: 10.1016/j.bjoms.2016.08.022 [Epub ahead of print].

4. Herbert C, Kent S, Magennis P, Cleland J. What causes trainees to leave oral and maxillofacial surgery? A questionnaire survey. Br J Oral Maxillofac Surg 2016; doi: 10.1016/j.bjoms.2016.08.023 [Epub ahead of print].

DOI: 10.1038/sj.bdj.2016.801

\section{Erratum \\ Transforming the registers}

The above letter, published on 23 September 2016 (221: 280), was erroneously published with only one reference listed at the end, although three references are cited in the text of the letter. The full reference list should have been published as follows:

General Dental Council. Consultation on removal of registrants' full addresses from the online register. Available at: http://www.gdc-uk.org/ GDCcalendar/Consultations/Pages/removal-of-registrants\%E2\%80\%99-full-addresses-from-the-online-register.aspx (accessed July 2016).

2. General Medical Council. Consultation on developing our online register. Available at: http:// www.gmc-uk.org/doctors/LRMPconsultation.asp (accessed July 2016).

3. General Medical Council. Reviewing the List of Registered Medical Practitioners (LRMP): options for development. Available at: http://www.gmc-uk.org/ about/research/26683.asp (accessed July 2016).

We apologise to Dr C. Albert Yeung for this error and for the inconvenience caused.

DOI: $10.1038 /$ sj.bdj.2016.802 